\title{
Acquisition variables in human avoidance behavior
}

\author{
FRANK D. MILLER, RICHARD S. KALIN, WILLIAM N. ECKENROTH \\ and \\ PHILIP A. MEYER* \\ University of South Dakota, Vermillion, S. Dak. 57069
}

Human Ss were given avoidance training employing a blast of pressurized air directly behind the ear as the aversive stimulus, a button depression as the avoidance response, and a light as the warning signal. The contents of four sets of instructions were varied with regard to the "information about the study." Better avoidance performance was obtained for the more informed conditions. The use of an escape contingency was not critical to response acquisition. Resistance to extinction appeared quite strong, and the suddenness of conditioning resembled all-or-none learning.

Avoidance conditioning with animals has received considerable empirical and theoretical attention (cf. Beecroft, 1967; Bolles, 1970; Herrnstein, 1969). While there is also clinical and theoretical interest in human avoidance behavior (Eysenck \& Rachman, 1965; Ullmann \& Krasner, 1969; Wolpe \& Lazarus, 1966), only a few systematic studies have been conducted (e.g., Turner \& Solomon, 1962). This deficiency may in part be due to the lack of a suitable research technique for the study of avoidance conditioning in humans. One purpose of the present report was to describe such a technique, which employs as the aversive stimulus a blast of pressurized air to the mastoid process behind the ear. In the present study, the level of instructions required for efficient conditioning and the usefulness of an escape contingency were investigated. Extinction behavior was also assessed.

It was assumed that the effectiveness of the avoidance-conditioning technique would vary as a function of the amount of information given in the instructions prior to the experiment. Both Stone (1961) and Turner \& Solomon (1962) have failed to show differences in avoidance behavior between two sets of instructions. These failures may have resulted from relatively small differences in overall information between the instructions used. Consequently, a wider range of information was employed in the present investigation.

A second contingency manipulated in the present study was whether or not $S$ could escape the air blast after having failed to make a Ra. If $S$ failed to make a $\mathrm{Ra}$ in the avoidance-escape (AE) condition, a button depression could terminate the air blast after its onset. The $S s$ in the avoidance-only (AO) condition could not terminate the air blast after having failed to

*Requests for reprints should be sent to Philip A. Meyer, Department of Psychology, University of South Dakota, Vermillion, S. Dak. 57069. make a $\mathrm{Ra}$. The results of animal research comparing $\mathrm{AE}$ with $\mathrm{AO}$ conditions have been equivocal. However, theoretical analysis of these varied results has been offered by Bolles (1970).

In the present experiment, four sets of instructions, which varied the amount of information given the $S$, were factorially combined with the $A E$ vs $A O$ variable.

\section{SUBJECTS}

The Ss were 64 students selected from an introductory psychology course at the University of South Dakota. APPARATUS

The apparatus consisted of a response button; a dental chair with adjustable arms, seat, back, and head rest; an air-delivery system; a white light; and switching and timing circuitry. The spring-loaded circular response button was mounted on the end of a cylindrical hand grip which was $1 \frac{1}{2}$ in. in diam and $4 \mathrm{in}$. long. In its normal position the button protruded $1 / 2$ in. from the end of the hand grip. The hand grip was placed on the right arm of the chair but could be picked up and held by $S$ in the right hand.

The air-delivery system consisted of a 1/2-hp single-stage electric compressor, a $40-\mathrm{ft}$ length of rubber hose, a valve capable of delivering pressures from 5 to $110 \mathrm{psi}$, a pressure regulator guage, a solenoid valve, and a 1/8-in. metal nozzle. A $7 \frac{1}{2}-\mathrm{W}$ white light, which served as the signal, was mounted on a wall, $6 \mathrm{ft}$ in front of S's head.

The circuitry necessary for stimulus presentations, timing of intervals, and recording response latency was provided by relay switches, Hunter Decade interval timers, and a Hunter KlocKounter. The timers and associated circuitry were used to program the series of trials and to control signal, air blast, interstimulus interval (ISI), and intertrial interval (ITI). The circuit was wired so that Ss were prevented from avoiding or escaping the air blast by continuously holding down the response button. Additional equipment included an earplug, two ace bandages, and a mirror.

\section{PROCEDURE}

The Ss were ushered into an experimental room and told by $E$ to sit in the dental chair. After the chair was adjusted so that $S$ was seated comfortably, $S$ was handed a typewritten card of instructions and asked to read it. When $S$ returned the instruction card and placed the earplug in his right ear, E securely tied one ace bandage around S's forehead and the other around his midsection. The end of the air nozzle was positioned $1 / 4$ in. from the mastoid portion of the temporal bone behind S's right pinna. The air nozzle was directed so that it formed a 45-deg angle with the side of S's head. The point of impact of the air was on the mastoid bone, midway between the upper and lower edges of the pinna and $1 / 2$ in. behind the crevice separating the bone and pinna. The $E$ then went behind a partition to a desk, where the mirror and timing equipment were located. The mirror was positioned so that $E$ could observe $S$ throughout the experiment.

Eight Ss (four male and four female) were randomly assigned to each of eight cells of a 4 by 2 factorial design in which four sets of instructions varying on a continuum from "least to most complete information" were made orthogonal to two response contingencies. The least-complete set of instructions (Set 1) read as follows: "Read these instructions carefully. I am not allowed to give you any additional information, so please do not ask me any questions. Place the earplug located on the arm of the chair in your right ear and rest your head in the head rest. (There is a way for you to control what happens to you during the experiment.) When you have finished reading these instructions, return this card to the experimenter. The experimenter will then attach a strap around your head and one around your chest. Keep your head in the same position throughout the course of the experiment."

The three remaining sets of instructions were identical to Set 1 , except the sentence contained in parentheses was deleted and other sentences were inserted. In Set 2 the sentence inserted was: "Pick up the silver hand grip and hold it in your right hand." The sentences inserted in Set 3 were: "Pick up the silver grip and hold it in your right hand. You are permitted to press the button on the grip during the experiment." In Set 4 the sentences inserted were: "From time to time during the course of the experiment, you will receive a blast of pressurized air behind your right ear. The blast of air will always be preceded by the onset of the white light mounted on the wall in front of you. Pick up the silver 
Table 1

Mean Trials to Criterion. Mean Number of Avoidance Responses. Number of Ss Conditioning. and Mean Number of Escape Responses During Acquisition as a Function of the Presence $(A E)$ or Absence $(A O)$ of an Escape Contingency and Instruction Set

\begin{tabular}{|c|c|c|c|c|}
\hline \multirow{2}{*}{$\begin{array}{l}\text { Escape } \\
\text { Contin- } \\
\text { gency }\end{array}$} & \multicolumn{4}{|c|}{ Instrustion Set } \\
\hline & 1 & 2 & 3 & 4 \\
\hline & \multicolumn{4}{|c|}{ Mean Trials to Criterion } \\
\hline $\mathrm{AE}$ & 14.5 & 29.9 & 23.9 & 3.1 \\
\hline AO & 29.9 & 26.8 & 19.6 & 3.0 \\
\hline \multicolumn{5}{|c|}{ Mean Number of Avoidance Responses } \\
\hline $\mathrm{AE}$ & 29.4 & 12.9 & 18.9 & 39.9 \\
\hline AO & 13.4 & 16.8 & 19.6 & 39.8 \\
\hline \multicolumn{5}{|c|}{ Number of Ss Conditioning } \\
\hline$A E$ & 6 & 4 & 5 & 8 \\
\hline $\mathrm{AO}$ & 3 & 6 & 5 & 8 \\
\hline \multicolumn{5}{|c|}{ Mean Num } \\
\hline $\mathrm{AE}$ & 5.5 & 5.9 & 7.1 & 0.1 \\
\hline $\mathrm{AO}$ & 4.3 & 4.8 & 4.0 & 0.3 \\
\hline
\end{tabular}

hand grip and hold it in your right hand. If you press the button located on the grip when the light is on, you can prevent the occurrence of the air blast."

The two response contingencies refer to whether $\mathrm{S}$ was allowed to escape the air blast on a trial after he had failed to make a $\mathrm{Ra}$. In the avoidance-escape (AE) condition, $\mathbf{S}$ could prevent the occurrence of the air blast by making a button depression during the ISI (i.e., a Ra). In addition, a button depression following the onset of the air blast immediately terminated it (i.e., an escape response). The $\mathrm{Ss}$ in the avoidance-only (AO) condition could avoid the air blast by responding during the ISI but could not escape it by responding after air-blast onset.

Forty acquisition trials were run according to the experimental conditions to which $S$ was assigned. The signal, which terminated simultaneously with onset of the aversive stimulus, was presented for a maximum duration of $2 \mathrm{sec}$. The 40-psi blast of pressurized air to the right mastoid process, which served as the aversive stimulus, was presented for a maximum duration of 6 sec. A Ra during the ISI (i.e., time from light onset to air-blast onset) immediately terminated the light and prevented the air blast. Total trial time, time from light onset to scheduled air-blast offset, was $8 \mathrm{sec}$. The ITI, time from offset of the air blast to onset of the light on the next trial, was $5 \mathrm{sec}$. The time from light onset on any trial to light onset on the next trial was a constant $13 \mathrm{sec}$. This was true even for those trials on which $S$ avoided, because the time period for the occurrence of the light, the air blast, and the ITI were included on these trials. Immediately following acquisition, all Ss were administered 40 typical extinction trials. On these trials the signal light continued to occur at the predetermined interval as in acquisition. but the air blast was no longer programmed. A button depression during the light terminated it inmediately.

During acquisition and extinction. $E$. recorded response latency on each trial to the nearest $0.01 \mathrm{sec}$. Following the last extinction trial, $E$ turned off the timers, untied the ace bandages, and asked $S$ to return the earplug. The $\mathrm{S}$ was then required to fill out an 18-item questionnaire which provided information about possible prior knowledge of the study, reaction to the air blast, concept of the relationship between the light and the air blast, recall of the instructions, and other such matters. Each $\mathrm{S}$ was then asked to read a paragraph which petitioned him not to discuss the experiment with others and thanked him for his participation.

\section{RESUITS AND DISCUSSION}

Mean number of trials to a three-successive-response criterion (TC3), mean number of Ras, and the number of Ss reaching the criterion in acquisition are presented for each group in Table 1. For Ss who did not condition in 40 trials, a TC3 score of 43 was assigned. Most groups contained Ss who both did and did not reach criterion. Thus, a nonnormal, bimodal distribution existed for the group data. As a result, nonparametric statistical analyses were used throughout. In the $\mathrm{AO}$ condition Ss given the higher numbered instruction sets evidenced more avoidance responding. Kruskal-Wallis one-way analyses of variance by ranks performed on the four AO groups for both the TC3 and number of Ras data provided statistical support for this trend. Group differences were significant for mean TC 3 and number of Ras (Hs=17.93 and 16.70, dfs $=3$, respectively, $p<.001)$. Identical analyses were performed on the same measures for the four $\mathrm{AE}$ groups as well. Again, there was a trend for the higher numbered sets of instructions to produce greater performance. However, $S s$ in the least-informed group (Set 1) performed at an intermediate level. Nevertheless, the analyses for TC3 and number of Ras were both significant $(\mathrm{Hs}=19.21$ and 20.30, $\mathrm{dfs}=3$, respectively, $\mathrm{p}<.001$ ). Thus, the notion that instructions influence avoidance learning with generally better performance occurring in the more informed groups was supported.

Of the Ss who met the acquisition criterion, half (22) were in the $\mathrm{AE}$ condition. In addition, analyses of the $\mathrm{AE}$ vs AO variable never approached significance for either the TC3 or the number of Ras measures. Thus, no differences in performance attributable to the $\mathrm{AE}$ vs $\mathrm{AO}$ variable were noted. Also, given in Table 1 are the group mean number of escape responses. An escape response was defined as a button depression occurring during the air blast. The $\mathrm{Ss}$ in the $\mathrm{AE}$ condition generally made more escape responses: however, this apparent difference was not found to be reliable $(p>20)$ in any of several comparisons between individual and combined AE vs AO groups. Apparently, the escape contingency as employed here was not effective.

During acquisition, Ss conditioned at different trial points. yet an overall pattern for conditioning rate emerged. Of the 44 conditioners, 30 demonstrated one-trial acquisition. Having made a first response, these Ss continued to respond on all the following acquisition trials. An efficiency score was calculated for each $S$ who conditioned. This score consisted of taking the total number of Ras minus 1 and dividing the remainder by the number of acquisition trials remaining after the first $\mathrm{Ra}$. This quotient was then multiplied by 100. For the $30 \mathrm{Ss}$ conditioning in one trial, this efficiency score was $100 \%$. For all 44 conditioners the average efficiency was $97.7 \%$. The lowest group average was 83.3\%. In fact, only two Ss had efficiency scores below $94 \%$. It appears, therefore, that acquisition of avoidance in this situation is characteristically sudden, resembling all-or-none learning.

During the 40-trial extinction period, only 6 of the 44 Ss who had conditioned met the extinction criterion of five successive nonresponses. In five of the groups no Ss extinguished. Hence, no trend across groups was apparent during extinction, other than a generally strong resistance to extinction. The conclusion that Ss are highly persistent during extinction of the avoidance response is given further support by unpublished data from our laboratory, in which Ss continued to respond for 100 extinction trials (Bair, 1969). In this study, 48 Ss were conditioned with 40 acquisition trials, and 39 of these continued to respond throughout the entire 100-trial extinction period. Three additional Ss responded for 95 or more trials during extinction. The apparent high resistance to normal extinction produced by this methodology is consistent with the generally persistent nature of avoidance behavior (e.g., Beecroft, 1967, p. 66). Considering the recent interest in procedures that eliminate avoidance behavior (Bandura, 1969, Chap. 6), the further use of this technique to evaluate such procedures would appear warranted.

One feature of the present methodology is that the aversive stimulus is not painful. For example, Ss generally rated the air blast "objectionable" or "annoy ing" rather 
than "painful." This fact may account for the virtual absence of emotional behavior on the S's part. Apparently, the nonemotional characteristic of avoidance behavior in the present situation is not unique. D'Amato (1969, p. 108) has recently recounted some similar observations and has discussed the problem of avoidance without "fear." Summarily, these results are encouraging in regard to employing the air-blast technique to study human avoidance behavior. Most Ss are able to acquire a simple $\mathrm{Ra}$ with in 40 trials. Moreover, use of instructions that provide some degree of information concerning the situation seems desirable. However, the procedure of permitting escape as well as avoidance responses does not appear to be critical in establishing the behavior.

\section{REFERENCES}

BAIR, D. Effects of air blast intensity on the acquisition and extinction of a human avoidance response. Unpublished MA thesis, University of South Dakota, 1969.

BANDURA, A. Principles of behavior modification. New York: Holt, Rinehart, \&
Winston, 1969.

BEFCROFT, R. S. Imotional conditioning. Psychonomic Monograph Supplements. 1967. 2, 45-72.

BOLLES. R. C. Species-specific defense reactions and avoidance learning. Psychological Review, $1970,77,32-48$.

D'AMATO, M. R. Instrumental conditioning with negative reinforcement. In M. H. Marx (Ld.), Learning: Processes. London: Collier-Macmillan, 1969. Pp. 35-118.

EYSENCK, H. J., \& RACHMAN, S. The causes and cures of neurosis. San Diego, Calif: Knapp, 1965.

HERRNSTEIN, R. J. Method and theory in the study of avoidance. Psychological Review, 1969, 76, 49-69.

STONE, G. C. Nondiscriminated avoidance behavior in human subjects. Science, 1961, $133,641-642$

TURNER, L. H., \& SOLOMON, R. L. Human traumatic avoidance learning: Theory and experiments on the operant-respondent distinction and failures to learn. Psychological Monographs, 1962, 76(40, Whole No. 559).

ULLMAN, L. P., \& KRASNER, L. $A$ psychological approach to normal behavior. Englewood-Cliffs, N.J : Prentice-Hall, 1969.

WOLPE, J., \& LAZARUS, A. A. Behavior therapy techniques: $A$ guide to the treatment of neuroses. New York: Pergamon Press, 1966.

\title{
Retrieval of words from subordinate and superordinate categories in semantic hierarchies*
}

\author{
ELIZABETH F. LOFTUS, $\uparrow$ Stanford University, Stanford, Calif. 94305 \\ JONATHAN L. FREEDMAN, Columbia University, New York, N.Y. 10037 \\ and \\ GEOFFREY R. LOFTUS, Stanford University, Stanford, Calif. 94305
}

Retrieval from long-term memory was investigated in an experiment in which $\mathrm{S}$ was shown a category name and asked to respond with a word belonging to the category (e.g., animal-horse, bird-robin). The reaction time (RT) taken to re trieve a member of a given category was not significantly different from the time taken to retrieve a member of a superset of that category. For example, Ss could produce an instance of the category "bird" as quickly as they could produce an instance of the category "animal." The time taken to retrieve a category member was found to be strongly related to the Thorndike-Lorge frequency of the most frequent category member. The data support the notion of a semantic organization in which the category name can be located directly, rather than being accessible only via a search along a hierarchical path.

Every word that is part of our semantic memory belongs to an extensive network of associations and can be categorized in various ways. Current theories treat long-term memory as though it consisted of a large number of interconnected and cross-referenced associative and category

\footnotetext{
*The authors wish to thank Lauren Dyer who patiently collected the data. The study was supported in part by a National Science Foundation grant to J. Freedman and was conducted while E. Loftus was on a Public Health Service Fellowship.

$\dagger$ Now at the New School for Social Rescarch.
}

networks (e.g., Pollio, 1968). Although it is not yet possible to provide precise details about these category networks, it may be fruitful to make general distinctions among possible types of networks and to determine what implications they have for retrieval.

One plausible model views memory as though it were organized as a single predefined hierarchy (Green, Wolf, Chomsky, \& Laughery, 1963; Lindsay, 1963). A search process is assumed to begin at the top of the hierarchy and to follow pathways downward through the network. Green et al's simulation program demonstrated that this kind of memory can be interrogated with natural language questions; Lindsay's program showed that such a memory structure can provide certain inference-making properties. If we accept this view of semantic organization, what are the implications for retrieval? A portion of a hypothetical memory structure might consist of "living thing," with "animal" and "vegetable" as subsets of it, the superset "bird" and "snake" as subsets of "animal," and "canary" and "robin" as instances of the subset "bird." If the category name cannot be located directly, but must be found by beginning at the top of the semantic hierarchy and searching downward through the hierarchy, the time required to retrieve an instance of any category should reflect the number of supersets through which $\mathbf{S}$ must move before finding the appropriate category. Thus, we would expect the time taken to retrieve an instance of the category "bird" to be greater than the time to retrieve an animal, because $\mathrm{S}$ must move through at least one extra superset to locate the category "bird." Note that we have operationally described the hierarchy by assuming that, for a superordinatesubordinate pair of categories such as animal-bird, the superordinate (which includes everything that belongs in the subordinate category) will be higher in the hierarchy. For any superordinatesubordinate pair, then, retrieving an instance of the superordinate category should, according to this model, take less time.

Another possible type of memory structure (cf. Quillian, 1967, 1968, and Collins \& Quillian, 1969) assumes that there is no predetermined hierarchy of supersets and subsets or of categories and subcategories. When a search process begins with a particular word, that word is the patriarch of its own separate hierarchy. For example, according to the model, the word "bird" heads its own hierarchy when a search process begins with "bird," while "animal" heads its own hierarchy when the search is for an animal. As such, the word is directly accessible by some central processor, instead of being accessible only via a search along a hierarchical path. Thus, there is no reason to expect any difference between the RT taken to retrieve an instance of the category "bird" and the RT taken to retrieve an instance of the category "animal." In general, it is not necessary for $S$ to search along a hierarchical path to retrieve a category name; rather, he can locate it directly and then produce the strongest correct association.

The present experiment was designed to 